\title{
High porosity cellulose nanopapers as reinforcement in multi-layer epoxy laminates
}

\author{
Andreas Mautner ${ }^{\mathrm{a}, \mathrm{b}, *}$, Wan M.F.W. Nawawi ${ }^{\mathrm{a}, \mathrm{b}, \mathrm{c}}$, Koon-Yang Lee ${ }^{\mathrm{d}}$, Alexander Bismarck ${ }^{\mathrm{a}, \mathrm{b}, \mathrm{e}, *}$ \\ ${ }^{a}$ Institute of Materials Chemistry \& Research, Polymer \& Composite Engineering (PaCE) Group, University of Vienna, Währingerstr. 42, A-1090 Vienna, Austria \\ ${ }^{\mathrm{b}}$ Polymer \& Composite Engineering (PaCE) Group, Department of Chemical Engineering, Imperial College London, South Kensington Campus, SW7 2AZ London, United \\ Kingdom \\ ${ }^{\mathrm{c}}$ Department of Biotechnology Engineering, International Islamic University Malaysia, P.O. Box 10, 50278 Kuala Lumpur, Malaysia \\ ${ }^{\mathrm{d}}$ Department of Aeronautics, Imperial College London, South Kensington Campus, SW7 2AZ London, United Kingdom \\ e Department of Mechanical Engineering, Faculty of Engineering and the Built Environment, University of Johannesburg, South Africa
}

\section{A R T I C L E I N F O}

\section{Keywords:}

Cellulose A

Laminates A

Prepreg A

Thermosetting resin A

\begin{abstract}
A B S T R A C T
Utilizing high-performance cellulose nanopapers as 2D-reinforcement for polymers allows for realizing highloading-fraction ( 80 vol-\%), high-performance (strength $>150 \mathrm{MPa}$, modulus $>10 \mathrm{GPa}$ ) laminated nanopaper reinforced epoxy composites. Such cellulose nanopapers are inherently dense, which renders them difficult to be impregnated with the epoxy-resin. High-porosity nanopapers facilitate better resin impregnation, truly utilizing the properties of single cellulose nanofibres instead of the nanofibre network. We report the use of highporosity (74\%) but low strength and modulus bacterial cellulose (BC) nanopapers, prepared from BC-in-ethanol dispersion, as reinforcement for epoxy-resin. High-porosity nanopapers allowed for full impregnation of the BCnanopapers with epoxy-resin. The resulting BC-reinforced epoxy-laminates possessed high tensile modulus (9 GPa) and strength (100 MPa) at a BC loading of 30 vol- $\%$, resulting from very low void-fraction (3 vol- $\%$ ) of these papregs compared to conventional nanopaper-laminates $(10+$ vol.- $\%)$. Better resin impregnation of less dense nanocellulose networks allowed for maximum utilization of stiffness/strength of cellulose nanofibrils.
\end{abstract}

\section{Introduction}

Plants absorb and store $\mathrm{CO}_{2}$ during their growth period. Hence, utilizing plant-based materials could help mitigating climate change $[1,2]$. Unfortunately, plant derived materials, apart from wood, which is already a composite itself, cannot be used directly as engineering material. Thus, the composite concept is considered to be the solution to manufacture renewable materials with properties that match or exceed the performance of commonly used engineering polymers [3]. Consequently, there has been a rapid growth in the research and development of natural fibre reinforced polymer composites [4-7]. Moreover, the advent of nanocellulose (NC) as nanoreinforcement for polymers has pushed frontiers in this domain further. The major driving force for utilizing NC as reinforcement is the potential of exploiting the high tensile strength and modulus of cellulose nanomaterials [8]. The Young's modulus of cellulose nanofibrils was determined to be $114 \mathrm{GPa}$ using Raman spectroscopy [9] and the tensile strength of single cellulose nanofibrils was estimated to be at least 2 GPa [10-12], which makes them attractive as reinforcement for the production of high performance, green, and sustainable composites [13]. NCs can be prepared either using the "top-down" approach, by defibrillation of lignocellulosic biomass into nanofibrils (CNF) [14], or "bottom-up" biosynthesis of cellulose by bacteria [15], e.g. Komagataeibacter xylinus, is exploited to obtain very pure and crystalline (up to 90\%) [16] bacterial cellulose (BC). BC is directly generated as nanomaterial without the need for complex processing and nanostructuring procedures [17].

NC composites are commonly prepared by solvent casting or meltblending in an extruder [18]. Unfortunately, these approaches often suffer from (i) insufficient dispersion of NCs, (ii) long processing times, or (iii) poor fibril-matrix adhesion in case of unmodified NCs $[13,19]$. Accordingly, due to the intrinsic hydrophilicity of NCs and their tendency to agglomerate, achieving high fibre volume fraction $\left(v_{\mathrm{f}}\right) \mathrm{NC}$ composites is not a trivial task [20]. To enhance the NC weight fraction incorporated into composites, hydrophobization of NCs [20-23] or utilizing NCs in all-cellulose composites were explored [24]. A further approach is lamination of nanopaper networks as inspired by paper

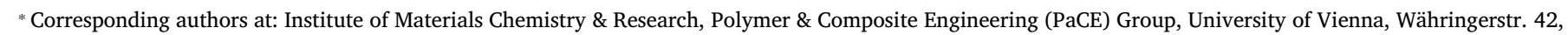
A-1090 Vienna, Austria.

E-mail addresses: andreas.mautner@univie.ac.at (A. Mautner), alexander.bismarck@univie.ac.at (A. Bismarck). 
based laminates (papregs) developed in the 1940s for the production of high strength renewable composites $[3,25]$. Utilizing nanopapers as $2 \mathrm{D}$ reinforcement in a lamination process is expected to yield high $v_{\mathrm{f}}$, high strength cellulose nanocomposites due to the high nanopaper strength without the need to modify NCs $[26,27]$. Nanopaper composites were typically produced by impregnation with a liquid resin or polymer solution, often preceded by a solvent exchange step [28-37], and had tensile strengths ranging from 48 to $152 \mathrm{MPa}$ at $v_{\mathrm{f}}$ between 15 and $80 \%$. Importantly, these structures generally contained only one nanopaper layer, which inherently limited the thickness of the final composites. However, in order to develop useful composites other than veneer with thicknesses of about $100 \mu \mathrm{m}$, multi-layer nanopaper laminated composites are required [38]. So far, only a few studies reported multi-layer nanopaper composites produced by vacuum assisted resin infusion or utilizing thermoplastic materials [27,39-41]. Previously, it was demonstrated that lamination of nanopapers with liquid epoxy-resin is an easily scalable composite production process [38] in which the mechanical properties of high $v_{\mathrm{f}}$ nanopaper papregs were determined by the nanopaper properties [42-44].

Contrary to conventional papers, nanopapers usually have higher envelope densities and consequently lower porosities $[45,46]$, which is responsible for their excellent mechanical properties. However, due to the low porosity of the nanopapers, full impregnation of the nanocellulose network with the matrix and thus effective load transfer was not achieved by lamination and hot-pressing $[38,39]$. This is currently one of the biggest issues in composite preparation by paper-lamination: incomplete impregnation of nanopaper networks by the matrix due to high nanopaper density $[36,47]$. In order to produce high performance papregs, the void fraction must be minimized [48] and therefore nanopapers with tailored porosity are desirable. One approach to increase the porosity of nanopapers in which nanocellulose fibrils are less densely packed is the dispersion of nanofibrils in organic solvents prior to the production of nanopapers [49], rather than just solvent exchanging an aqueous NC filter cake [31,50]. Preparing papers from BC dispersed in organic solvents results in decreased density and thus increased porosity of final BC nanopapers [49]. Even though those high-porosity nanopapers are expected exhibiting lower mechanical properties, we hypothesize that significantly higher porosity will allow for improved resin infusion into the nanocellulose network during composite production as compared to high-density nanopapers. This is of particular importance for the realization of multi-layer composites with high mechanical properties already at moderate $v_{\mathrm{f}}$. Hence better composites should be produced when using nanopapers of higher porosity as $2 \mathrm{D}$ reinforcement.

Here, we report the preparation of multi-layer laminated nanopaper composites exploiting synergistic effects resulting from the combination of low-strength but highly porous BC networks and an epoxy matrix of similar strength. Papregs were produced by lamination of two or four nanopapers with one or three layers of epoxy resin, respectively. High porosity nanopapers were prepared by dispersing $\mathrm{BC}$ fibrils in ethanol prior to papermaking, rather than just treatment of a wet aqueous $\mathrm{BC}$ filter cake with organic solvents to increase nanopaper porosity. Multilayer laminated nanopaper epoxy resin prepregs, as opposed to singlelayer composites commonly prepared, were manufactured and cured in a hot-press. Mechanical properties and thermal behaviour of these papregs are reported.

\section{Materials \& methods}

\subsection{Materials}

Bacterial cellulose (BC) was kindly supplied by fzmb GmbH (Bad Langensalza, Germany) in the form of wet pellicles containing $92 \mathrm{wt}-\%$ water. These BC fibrils possessed a diameter of approximately 30 to $50 \mathrm{~nm}$ and fibril lengths of up to several micrometres (see Fig. S1 in the supporting information). Ethanol (EtOH, purity $>$ 99.8\%) was purchased from Sigma-Aldrich (Dorset, UK) and used as received. Epoxy resin (Araldite LY556) and an amine-based hardener (XB3473) were purchased from Mouldlife Ltd. (Suffolk, UK). Deionized water was used throughout all experiments.

\subsection{Manufacturing of $B C$ nanopapers}

In this work, BC nanopapers with grammages of $49 \pm 2$ and $62 \pm 4 \mathrm{~g} \mathrm{~m}^{-2}$ (gsm) were produced following a previously described protocol [46]. Briefly, BC pellicles were first cut into small pieces of approximately 5-10 $\mathrm{mm}$ and blended at a consistency of $0.2 \mathrm{wt}-\%$ in deionized water for 2 min using a kitchen blender (Breville VBL065-01, Oldham, UK) to produce a BC-in-water suspension. This suspension was then vacuum filtered onto a $125 \mathrm{~mm}$ diameter cellulose filter paper (Grade 413, particle retention $=5-13 \mu \mathrm{m}$, VWR International Ltd., Lutterworth, UK). The wet BC filter cake was then carefully removed from the filter paper used and wet pressed between two fresh blotting papers (3MM Chr VWR, Lutterworth, UK) under a weight of $10 \mathrm{~kg}$ for 5 min to further remove the excess water. After wet pressing, the solid content of the wet BC filter cake was found to be approximately $15 \mathrm{wt}-$ $\%$. This wet BC filter cake was then placed between fresh blotting papers, sandwiched between two metal plates and heat consolidated in a hydraulic press (25-12-2H, Carver Inc., Wabash, USA) at $120^{\circ} \mathrm{C}$ for $1 \mathrm{~h}$ under a weight of $1 \mathrm{t}$. BC nanopapers produced from BC-in-water suspension are herein termed $\mathrm{BC}$-aq. $\mathrm{BC}$ nanopapers were also produced from BC-in-ethanol suspensions. To produce these BC nanopapers, a BCin-water suspension was first prepared following the protocol described previously and vacuum filtered onto a $125 \mathrm{~mm}$ diameter cellulose filter paper as previously described. Instead of a wet pressing step, the wet BC filter cake was carefully removed from the used filter paper and redispersed in ethanol overnight using an orbital shaker (IKA KS260 Basics, Camlab, Cambridge, UK). This BC-in-ethanol suspension was then consolidated into BC nanopaper following the previously described vacuum filtration, wet pressing, and heat consolidation steps. BC nanopapers produced from BC-in-ethanol suspension are herein termed BC-Et.

\subsection{Manufacturing of laminated epoxy composites consisting of multi-layer $B C$ nanopapers}

Two types of laminated multi-layer BC nanopaper epoxy composites were manufactured: laminated composites consisting of (i) two BC nanopapers and a layer of epoxy resin in between (herein termed composite $2 \mathrm{~L}$ ), and (ii) four $\mathrm{BC}$ nanopapers and three layers of epoxy resin in between (herein termed composite $4 \mathrm{~L}$ ). The uncured epoxy resin and the amine-based hardener were mixed at a weight ratio of 100:23, degassed under reduced pressure (10 mbar) for $10 \mathrm{~min}$ at $80^{\circ} \mathrm{C}$ and then cooled to room temperature prior to lamination (Printing Proofer, PrintCoat Instruments Ltd., Hertfordshire, UK). To manufacture composite $2 \mathrm{~L}$, the degassed epoxy resin was coated on a $\mathrm{BC}$ nanopaper which was covered and laminated with another (uncoated) BC nanopaper. To manufacture composite 4L, a laminated 2 layer sandwich was recoated with resin and laminated with a third paper and the three layer sandwich subsequently with a fourth layer. The thickness of the applied resin layer was set to be $50 \mu \mathrm{m}$ for BC-aq and $90 \mu \mathrm{m}$ for BC-Et due to differences in nanopaper porosity and hence resin permeability of the $\mathrm{BC}$ nanopapers (see results and discussion later). The laminated samples were then sandwiched between two Teflon films in a custom made mould (diameter $125 \mathrm{~mm}$ ) and cross-linked in a heated hydraulic press (25-12-2H, Carver Inc., Wabash, USA) at $120^{\circ} \mathrm{C}$ under a weight of $2 \mathrm{t}$ for $2 \mathrm{~h}$, followed by a post-curing step at $180^{\circ} \mathrm{C}$ for $4 \mathrm{~h}$. After this, the laminated composites were cooled to room temperature under the same compaction pressure prior to de-moulding. The weight fraction of $\mathrm{BC}\left(w_{\mathrm{f}}\right)$ in the composites were $90 \mathrm{wt}-\%$ for laminate 2L-BC-aq, $87 \mathrm{wt}-\%$ for laminate $2 \mathrm{~L}-\mathrm{BC}-\mathrm{Et}, 39 \mathrm{wt}-\%$ for laminate $4 \mathrm{~L}-\mathrm{BC}-\mathrm{aq}$, and $40 \mathrm{wt} \%$ for laminate $4 \mathrm{~L}-\mathrm{BC}-\mathrm{Et}$, respectively. As a 
control, unreinforced neat epoxy resin specimens were produced by casting the mixed and degassed resin into a Teflon mould with dimensions of $40 \times 5 \times 2 \mathrm{~mm}^{3}$ followed by curing in an oven at $120{ }^{\circ} \mathrm{C}$ for $2 \mathrm{~h}$ and then for $4 \mathrm{~h}$ at $180{ }^{\circ} \mathrm{C}$.

\subsection{Characterization of fabricated BC nanopapers}

\subsubsection{Grammage, density, and porosity of BC nanopapers}

The grammage $(G)$ of fabricated BC nanopapers was calculated from the ratio of mass $(m)$ and its projected area $(A)$. The thickness $(d)$ of the fabricated nanopapers was measured using a digital micrometer (Model 705-1229, RS components, Corby, UK). With $G$ and $d$ known, the envelope density $\left(\rho_{\mathrm{e}}\right)$ of the fabricated $\mathrm{BC}$ nanopaper was calculated as the ratio between $G$ and $d$. The porosity of the BC nanopapers $(P)$ was then determined using:

$P=1-\frac{\rho_{\mathrm{e}}}{\rho_{\mathrm{c}}}$

taking the cellulose true density $\left(\rho_{\mathrm{c}}\right)$ of $1500 \mathrm{~kg} \mathrm{~m}^{-3}$ [51].

\subsubsection{Specific surface area of $B C$ nanopapers}

Specific surface area (SSA) measurements based on $\mathrm{N}_{2}$ adsorption/ desorption isotherms were performed to determine the specific surface area of BC nanopapers using a surface area and porosity analyser (TriStar 3000, Micrometrics Ltd, Dunstable, UK). The specific surface area was calculated using the Brunauer-Emmett-Teller (BET) equation. Prior to the measurement, all samples were conditioned in $\mathrm{N}_{2}$ at $120{ }^{\circ} \mathrm{C}$ overnight to remove any adsorbed moisture.

\subsubsection{Tensile properties of $B C$ nanopapers}

Dog bone shape test specimens were cut from the samples using a punch die (Zwick ZCP 020 Manual Cutting Press, Zwick, Ulm, Germany). The specimens possessed an overall length of $35 \mathrm{~mm}$, a gauge length of $12 \mathrm{~mm}$, and the gauge section a width of $2 \mathrm{~mm}$. Prior to the test, all test specimens were secured on testing cards using a twocomponent cold curing epoxy resin (Araldite 2011, Huntsman Advanced Materials, Cambridge, UK) to prevent clamping damage of the test specimens in the tensile testing equipment. Tensile tests were conducted using a TST350 tensile tester (Linkam Scientific Instruments, Surrey, UK). A $200 \mathrm{~N}$ load cell and crosshead speed of $1 \mathrm{~mm} \mathrm{~min}{ }^{-1}$ were used. The sample thickness was determined using a digital micrometer and six specimens were tested and averaged for each type of $\mathrm{BC}$ nanopaper. The compliance of the tensile tester was determined to be $6.38 \times 10^{-3} \mathrm{~mm} \mathrm{~N}^{-1}$, which was taken into account when calculating the tensile modulus of the $\mathrm{BC}$ nanopapers.

\subsection{Characterization of the fabricated laminated BC nanopaper composites}

\subsubsection{Density and porosity of laminated composites}

Prior to calculating the porosity (void fraction) of the composites, the theoretical density of the composites $\left(\rho_{\text {th }}\right)$ was first evaluated using [31]:

$\rho_{\text {th }}=\frac{1}{\frac{w_{\mathrm{f}}}{\rho_{\text {epoxy }}}+\frac{1-w_{\mathrm{f}}}{\rho_{\mathrm{c}}}}$

in which $\rho_{\text {epoxy }}$ corresponds to the density of the cured epoxy resin. The void fraction of the composites $\left(v_{\mathrm{v}}\right)$ can then be calculated as follows:

$v_{\mathrm{v}}=1-\frac{\rho_{\text {comp }}}{\rho_{\text {th }}}$

where $\rho_{\text {comp }}$ denotes the envelope density of the laminated BC nanopaper composites, determined from the ratio between the mass and envelope volume of the composite samples. With $v_{\mathrm{v}}$ known, the volume fraction of $\mathrm{BC}$ in the laminated composites can be obtained from [31]: $v_{\mathrm{f}}=\frac{\rho_{\text {comp }}-\rho_{\text {epoxy }}\left(1-v_{\mathrm{v}}\right)}{\rho_{\mathrm{c}}-\rho_{\text {epoxy }}}$

\subsubsection{Internal morphology of laminated composites}

The morphology of the $\mathrm{BC}$ nanopaper-reinforced laminated composites was studied using scanning electron microscopy (SEM) (Jeol JCM-6000 Neoscope, Freising, Germany). Prior to SEM, the composite samples were frozen in liquid $\mathrm{N}_{2}$ and cryo-fractured using a pair of tweezers whilst the samples were still immersed in the liquid $\mathrm{N}_{2}$ bath. The samples were then sputter-coated with a thin layer of gold (Jeol JFC-1200 Fine Coater, Freising, Germany) at a coating current of $30 \mathrm{~mA}$ for $45 \mathrm{~s}$ prior to subsequent imaging.

\subsubsection{Tensile properties of laminated composites}

Rectangular test specimens with dimensions of $40 \times 5 \mathrm{~mm}^{2}$ were cut from the fabricated laminates. Prior to the tests, the thickness of all test specimens was measured at five different spots using a digital micrometer (705-1229, RS components, Corby, UK). Tensile tests were performed at $25{ }^{\circ} \mathrm{C}$ and $50 \% \mathrm{RH}$ using an Instron universal test frame (Model 5969 Dual Column Universal Testing System, Instron, Darmstadt, Germany) equipped with a $1 \mathrm{kN}$ load cell. The strain of the test specimens was monitored using a non-contact video extensometer (Gig ProE, iMetrium, Bristol, UK). The exposed length of the test specimens was $25 \mathrm{~mm}$ and the gauge length of the test specimen was set to be $15 \mathrm{~mm}$. A crosshead displacement speed of $1 \mathrm{~mm} \mathrm{~min}^{-1}$ was used. The tensile modulus of each specimen was determined from the linear elastic region of the stress-strain curves as secant between stress values separated by $0.2 \%$ strain.

\subsubsection{Viscoelastic properties of laminated composites}

The viscoelastic properties of the laminated composites were determined using dynamic mechanical thermal analysis (DMTA) (G2 RSA, TA Instruments, Eschborn, Germany) operated in tension mode. Rectangular test specimens with dimensions of $30 \times 5 \mathrm{~mm}^{2}$ were cut and tested between a temperature of $25^{\circ} \mathrm{C}$ and $250{ }^{\circ} \mathrm{C}$. A heating rate of $2{ }^{\circ} \mathrm{C} \mathrm{min}^{-1}$, a frequency of $1 \mathrm{~Hz}$, and an applied strain of $0.05 \%$ were used. The exposed length of the test specimen was set to be $15 \mathrm{~mm}$.

\subsubsection{Glass transition temperature of laminated composites}

Differential scanning calorimetry (DSC) (Discovery DSC, TA Instrument, Eschborn, Germany) was used to identify the glass transition temperature $\left(T_{\mathrm{g}}\right)$ of the laminated composites. Briefly, $5 \mathrm{mg}$ of samples were heated from $20{ }^{\circ} \mathrm{C}$ to $250{ }^{\circ} \mathrm{C}$ at a rate of $10{ }^{\circ} \mathrm{C} \mathrm{min}{ }^{-1}$, followed by a cooling step to $20^{\circ} \mathrm{C}$ at the same rate. The samples were then heated to $250{ }^{\circ} \mathrm{C}$ at a rate of $10{ }^{\circ} \mathrm{C} \mathrm{min}{ }^{-1}$.

\subsubsection{Thermal degradation behaviour of nanopapers and composites}

The thermal degradation behaviour of the fabricated BC nanopapers and the laminated composites in $\mathrm{N}_{2}$ and air was determined by thermogravimetric analysis (TGA) using high resolution modulated TGA (Discovery TGA, TA Instruments, Eschborn, Germany). Approximately $5 \mathrm{mg}$ of samples were heated from 30 to $650{ }^{\circ} \mathrm{C}$ at a rate of $10{ }^{\circ} \mathrm{C} \mathrm{min}{ }^{-1}$

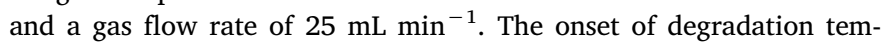
perature was computed from the temperature at which the rate of sample mass loss first exceeded $0.2 \%{ }^{\circ} \mathrm{C}^{-1}$.

\section{Results and discussion}

\subsection{Porosity and specific surface area of BC-aq and BC-Et nanopapers}

The envelope density, porosity, and specific surface area of BC-aq and BC-Et nanopapers are shown in Table 1. In this study, the grammages of BC-aq nanopapers were $49 \pm 2 \mathrm{~g} \mathrm{~m}^{-2}$ and $62 \pm 4 \mathrm{~g} \mathrm{~m}^{-2}$, respectively, and $33 \pm 1 \mathrm{~g} \mathrm{~m}^{-2}$ for BC-Et. BC nanopapers with different grammages were prepared in order to produce laminated 
Table 1

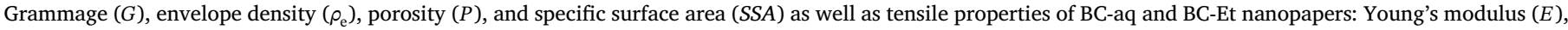
ultimate tensile strength $(\sigma)$, strain at break $(\varepsilon)$, and tensile index $(T I)$.

\begin{tabular}{|c|c|c|c|c|c|c|c|c|}
\hline BC nanopaper & $G(\mathrm{gsm})$ & $\rho_{\mathrm{e}}\left(\mathrm{kg} \mathrm{m}^{-3}\right)$ & $P(\%)$ & $S S A\left(\mathrm{~m}^{2} \mathrm{~g}^{-1}\right)$ & $E(\mathrm{GPa})$ & $\sigma(\mathrm{MPa})$ & $\varepsilon(\%)$ & $T I\left(\mathrm{~N} \mathrm{~m} \mathrm{~g}^{-1}\right)$ \\
\hline BC-aq 50 gsm & $49 \pm 2$ & $937 \pm 43$ & $38 \pm 2$ & - & $7.5 \pm 0.5$ & $136 \pm 9$ & $4.0 \pm 0.6$ & $128 \pm 12$ \\
\hline BC-aq $60 \mathrm{gsm}$ & $62 \pm 4$ & $974 \pm 57$ & $35 \pm 2$ & 18 & $8.3 \pm 1.6$ & $144 \pm 1$ & $4.7 \pm 0.5$ & $144 \pm 14$ \\
\hline BC-Et & $33 \pm 1$ & $392 \pm 7$ & $74 \pm 1$ & 90 & $1.3 \pm 0.1$ & $33 \pm 2$ & $5.6 \pm 0.2$ & $64 \pm 5$ \\
\hline
\end{tabular}

composites that will possess comparable thickness, as BC-Et nanopapers were thicker because of their significantly lower density. It can be seen from Table 1 that BC-aq nanopapers possessed a porosity of only $35-38 \%$. This value is consistent with the porosity of cellulose nanopapers fabricated from NC-in-water suspension reported by various researchers $[31,46,52]$. On the other hand, BC-Et nanopapers were found to possess a porosity of $74 \%$. Consequently, the specific surface area of BC-Et $\left(90 \mathrm{~m}^{2} \mathrm{~g}^{-1}\right)$ was also higher compared to BC-aq, which had a specific surface area of only $18 \mathrm{~m}^{2} \mathrm{~g}^{-1}$. The higher porosity and hence the higher surface area of BC-Et nanopapers can be explained by the formation of a looser hydrogen bonding network compared to BC-aq nanopapers during the consolidation stage. One possible explanation for this is the surface tension of the dispersing medium for BC. Ethanol has a surface tension of $22.2 \mathrm{mN} \mathrm{m}^{-1}$ whilst water has a surface tension of $72.8 \mathrm{mN} \mathrm{m}^{-1}$. This implies that smaller capillary forces will act on the $\mathrm{BC}$ nanofibres when manufacturing BC-Et nanopapers during the press-drying stage, leading to poorer packing efficiency. Furthermore, the lower grammage of BC-Et nanopapers might have contributed a little as well. The phenomenon of lower density of (nano)cellulose papers exposed to but not prepared from organic solvents was reported before $[31,53]$.

\subsection{Tensile properties of $B C$-aq and BC-Et nanopapers}

Representative tensile stress-strain curves of BC-aq and BC-Et nanopapers are shown in Fig. 1, with their tensile modulus, tensile strength, and strain-at-failure summarized in Table 1. BC-aq nanopapers possessed a tensile modulus and strength of $8.3 \mathrm{GPa}$ and $144 \mathrm{MPa}$ for $60 \mathrm{gsm}$ and $7.5 \mathrm{GPa}$ and $136 \mathrm{MPa}$ for $50 \mathrm{gsm}$, respectively, which is in good agreement with literature data [39,54-57]. When BC nanopapers were produced from BC-in-ethanol suspension, the resulting BC-Et nanopapers possessed lower tensile properties, with a measured tensile modulus and strength of only $1.3 \mathrm{GPa}$ and $33 \mathrm{MPa}$, respectively. The tensile properties of a cellulose (nano)fibre network is a function of the (nano)fibre modulus, degree of (nano)fibre-(nano)fibre bonding, (nano) fibre length and porosity of the (nano)fibre network [54]. Since the

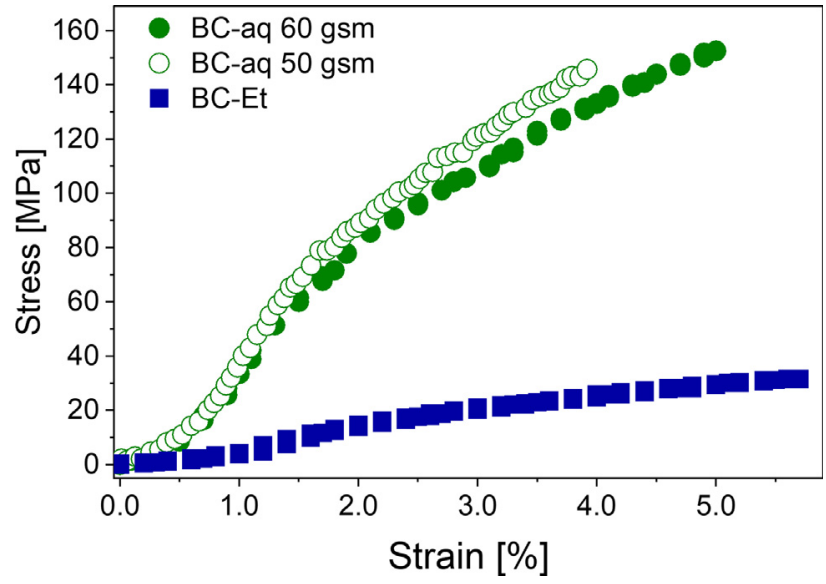

Fig. 1. Representative stress-strain curves of BC-aq and BC-Et nanopapers. (For interpretation of the references to colour in this figure legend, the reader is referred to the web version of this article.) same source of cellulose nanofibre was used (i.e. BC), the modulus of the nanofibre and the nanofibre length are the same for both BC-aq and BC-Et nanopapers. Therefore, the differences between the tensile properties of $\mathrm{BC}$-aq and $\mathrm{BC}$-Et nanopapers can be attributed to the variation in the porosity of the $\mathrm{BC}$ nanopapers.

In addition to this, the grammage of a $\mathrm{BC}$ nanopaper plays a significant role in the stress-transfer efficiency within the resulting nanopaper [58]. The lower the grammage of a $\mathrm{BC}$ nanopaper, the lower the coverage of $\mathrm{BC}$ nanofibre within the nanopaper [41]. As a result, lower grammage BC nanopapers possessed lower tensile properties compared to higher grammage BC nanopapers due to the poorer stress-transfer efficiency within the nanopaper, even when the nanopapers were made from a BC-in-water suspension. Similar results were also observed in this work. In addition to the higher porosity of BC-Et nanopapers, the grammage of BC-Et nanopapers is lower than that of BC-aq nanopapers. This further contributed to the lower tensile properties of BC-Et compared to BC-aq nanopapers, but the main contribution must still be attributed to their lower porosity. Furthermore, also reduced interfibril interactions between less densely packed BC fibrils contributed to the reduction of the strength and Young's modulus, as already reported for pulp fibre papers [59], which was confirmed by lower tensile index.

\subsection{Visual appearance of laminated BC-aq and BC-Et epoxy composites}

Fig. 2 shows the visual appearance of BC-aq and BC-Et nanopapers, and their resulting two-layer or four-layer laminated $\mathrm{BC}$ nanopaper composites. Even without resin, differences between BC-aq and BC-Et nanopapers can be observed. The reduced optical transparency of BC-Et compared to $\mathrm{BC}$-aq can be attributed to their higher porosity (see Table 1). Similar observations have also been made by Toivonen et al. [60], who reported that cellulose nanofibre networks produced from octane have higher light scattering coefficients compared to cellulose nanofibre networks produced from water. This anomalous light transport phenomenon was attributed to the presence of a wider distribution of pores and agglomerated nanofibres.

When BC-aq and BC-Et nanopapers were laminated with an epoxy resin and cured, the optical transparency of the resulting laminated

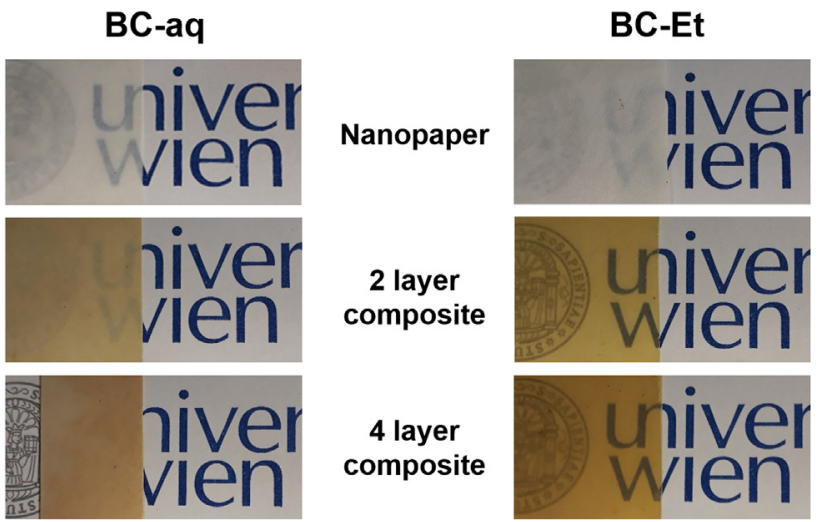

Fig. 2. Visual appearance of BC-aq (left) and BC-Et (right) nanopapers (top) as well as 2-layer (centre) and 4-layer (bottom) laminated nanopaper composites. (For interpretation of the references to colour in this figure legend, the reader is referred to the web version of this article.) 
Table 2

Physical data of laminates: density $\left(\rho_{\text {comp }}\right)$, fibre weight fraction $\left(w_{\mathrm{f}}\right)$, fibre volume fraction $\left(v_{\mathrm{f}}\right)$, and void volume fraction $\left(v_{\mathrm{v}}\right)$.

\begin{tabular}{lllll}
\hline Laminated composites & $\rho_{\text {comp }}\left(\mathrm{kg} \mathrm{m}^{-3}\right)$ & $w_{\mathrm{f}}(\%)$ & $v_{\mathrm{f}}(\%)$ & $v_{\mathrm{v}}(\%)$ \\
\hline 2L-BC-aq & $1200 \pm 30$ & $90 \pm 5$ & $71 \pm 5$ & $17.5 \pm 0.6$ \\
4L-BC-aq & $1170 \pm 40$ & $87 \pm 3$ & $68 \pm 3$ & $18.2 \pm 0.7$ \\
2L-BC-Et & $1170 \pm 30$ & $39 \pm 1$ & $30 \pm 1$ & $5.3 \pm 0.2$ \\
4L-BC-Et & $1210 \pm 30$ & $40 \pm 1$ & $33 \pm 1$ & $2.5 \pm 0.2$ \\
\hline
\end{tabular}

composites followed a different trend. BC-aq nanopapers were initially more transparent than BC-Et nanopapers. Upon lamination with an epoxy resin, the two-layer and four-layer laminated composites consisting of BC-aq nanopapers (2L-BC-aq and 4L-BC-aq) were no longer transparent. Instead, the two-layer and four-layer laminated composites consisting of BC-Et nanopapers (2L-BC-Et and 4L-BC-Et) were observed to be more optically transparent than their $\mathrm{BC}$-aq counterparts with only a slight yellowish colour of the amine cured epoxy resin (see Fig. S2, supporting information, which shows transparency and yellow colour of a pure cured epoxy resin specimen). The higher porosity of BC-Et nanopapers allowed for much better resin infusion into the fibril network, which was also reflected in the density of the composites (Table 2). The bi-layer BC-aq laminates had only slightly higher density (1200 $\mathrm{kg} \mathrm{m}^{-3}$ ) compared to the 2L-BC-Et laminates, which was attributed to the high density of the nanopapers and higher density of cellulose compared to the epoxy resin $\left(1180 \mathrm{~kg} \mathrm{~m}^{-3}\right)$. However, $4 \mathrm{~L}-\mathrm{BC}$ Et nanopaper laminates exhibited the highest composite density in this study $\left(1210 \mathrm{~kg} \mathrm{~m}^{-3}\right)$, which indicated low void volume content $\left(v_{\mathrm{v}}\right)$.

Physical data of the laminates are summarized in Table 2 and Table S1 (supporting information). The thickness of all composites was lower than the cumulative thickness of the individual nanopapers they were composed of. Accountable for this was further compression of the nanopapers during the composite manufacturing process. This was particularly true for the BC-Et papregs for which the cured plie thickness decreased by $15 \%$ resulting in lower $v_{\mathrm{v}}$ of the laminated BC nanopaper composites. Successful infusion of the nanopaper networks with epoxy resin was also evident by the increased grammage, in particular for BCEt laminates which almost tripled, thus explaining the translucent appearance. On the contrary, the grammage of BC-aq nanopapers increased only by 10 to $20 \%$ after resin impregnation, which indicated that only a small amount of resin actually entered the nanopaper network. A pure resin layer separated the BC sheets (Fig. 3), which explained their opaque appearance. Importantly, $v_{\mathrm{v}}$ of the 2 layer papreg was significantly higher for $2 \mathrm{~L}-\mathrm{BC}$-aq ( $18 \%$ vs. $5 \%$ for $2 \mathrm{~L}-\mathrm{BC}-\mathrm{Et})$. Also, in the case of 4 layer laminated papregs, the BC-Et network (original porosity $=74 \%)$ was almost completely impregnated $\left(v_{\mathrm{v}}=3 \%\right)$, while the $4 \mathrm{~L}-\mathrm{BC}$-aq composite had a $v_{\mathrm{v}}$ of $18 \%$, thus being much closer to the void content of the nanopapers themselves (35\%). This indicated that about half of the volume of the BC-aq network remained non- impregnated. A $v_{\mathrm{v}}$ of only $3 \%$ for the $4 \mathrm{~L}-\mathrm{BC}$-Et laminate was superior to results presented for composites containing nanopapers post-treated with organic solvents $(17-30 \%)$ [31] confirming the hypothesis that increased nanopaper porosity in conjunction with a lamination process and hot-pressing can facilitate almost complete resin infusion into a NC network.

\subsubsection{Microstructure of laminated nanopaper composites}

SEM images of fracture surfaces of 2L-BC-aq and 2L-BC-Et laminates show the layered structure of the cellulose nanopapers, which has been observed previously [61], present in both types of composites (Fig. 3). However, there were distinct differences; In 2L-BC-aq, the nanopaper sheets were clearly separated by a resin layer (Fig. 3, left), while laminates made using BC-Et nanoapers (Fig. 3, right) were homogeneous with the layered structure of the nanopapers appearing disturbed and no distinct matrix phase could be observed, indicating that the resin did indeed fully impregnate the nanopaper network.

The differences observed for 2L-BC-aq and 2L-BC-Et were also present in the four-layer versions (Fig. 4). Clearly, three distinct cured resin films could be observed in 4L-BC-aq (Fig. 4, left), whereas no such resin layers but only resin pockets were present in the laminated 4L-BC-Et composite (Fig. 4, right). Just as in the two-layer laminates, also here the fibril network was homogeneously infused with the epoxy resin explaining both the transparency of BC-Et laminates and low $v_{\mathrm{v}}$. In Fig. 4 (left) also voids were clearly visible within 4L-BC-aq.

\subsection{Mechanical properties of laminated nanopaper composites}

Characteristic stress strain curves of BC-Et and BC-aq laminates are shown in Fig. 5. 2L and 4L laminates, respectively, of both BC-Et and BC-aq were congruent and differed only in the ultimate strength and strain-to-failure. 2L-BC-aq laminates had higher tensile strength compared to 4L-BC-aq laminates, which was caused by their slightly higher $v_{\mathrm{f}}$. Furthermore, a higher number of dense nanopaper reinforcement layers increased the likelihood that flaws present in the network cause premature failure, hence, the ultimate tensile strength was reduced [40]. On the contrary, the 4L-BC-Et laminates had a slightly higher tensile strength and also strain-to-break compared to the 2L-BC-Et laminates. Between 2L and 4L-BC-Et, only a small difference of the (low) $v_{\mathrm{f}}$ was determined and increased laminate thickness might have resulted in reduced flaw sensitivity of the more porous nanopapers. Despite of having only half the $v_{\mathrm{f}}$ of 4L-BC-aq laminates, 4L-BC-Et had the same tensile strength and even higher strain-to-failure. The tensile strength was also three times higher than $\sigma$ of the neat epoxy resin (38 MPa). This proved that utilizing higher porosity papers in laminated nanopaper composites allowed for better resin impregnation of the BC fibril network, which was in particular true for multi-layer laminated composites. While better resin impregnation of BC-Et nanopapers resulted in higher tensile strength and strain-to-failure for the $4 \mathrm{~L}$

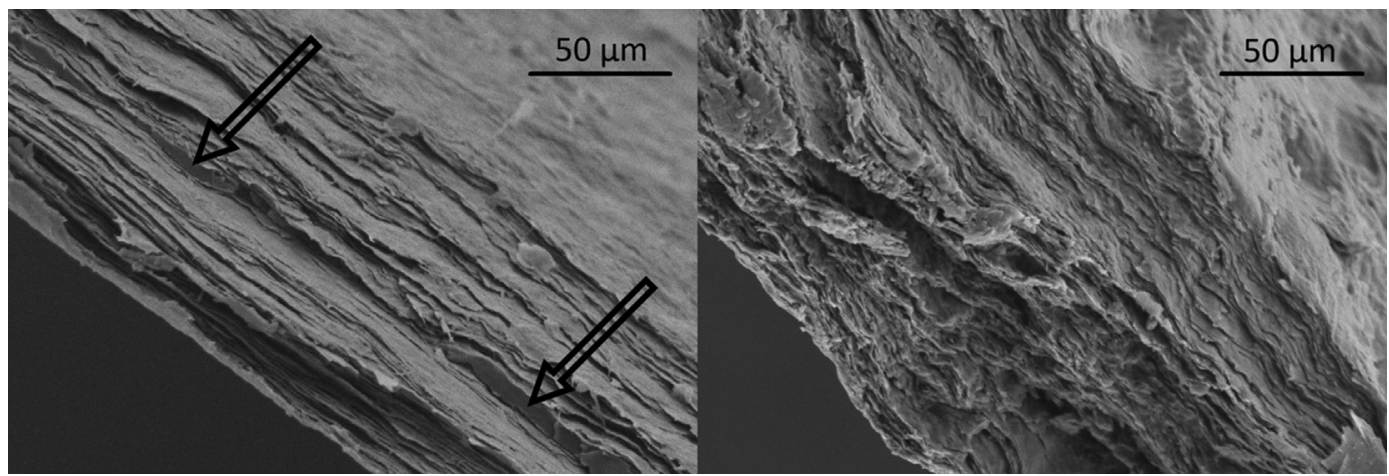

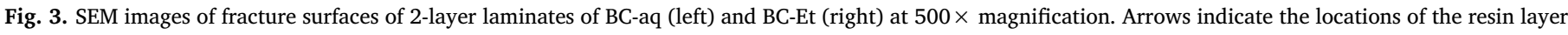
separating the nanopapers. 


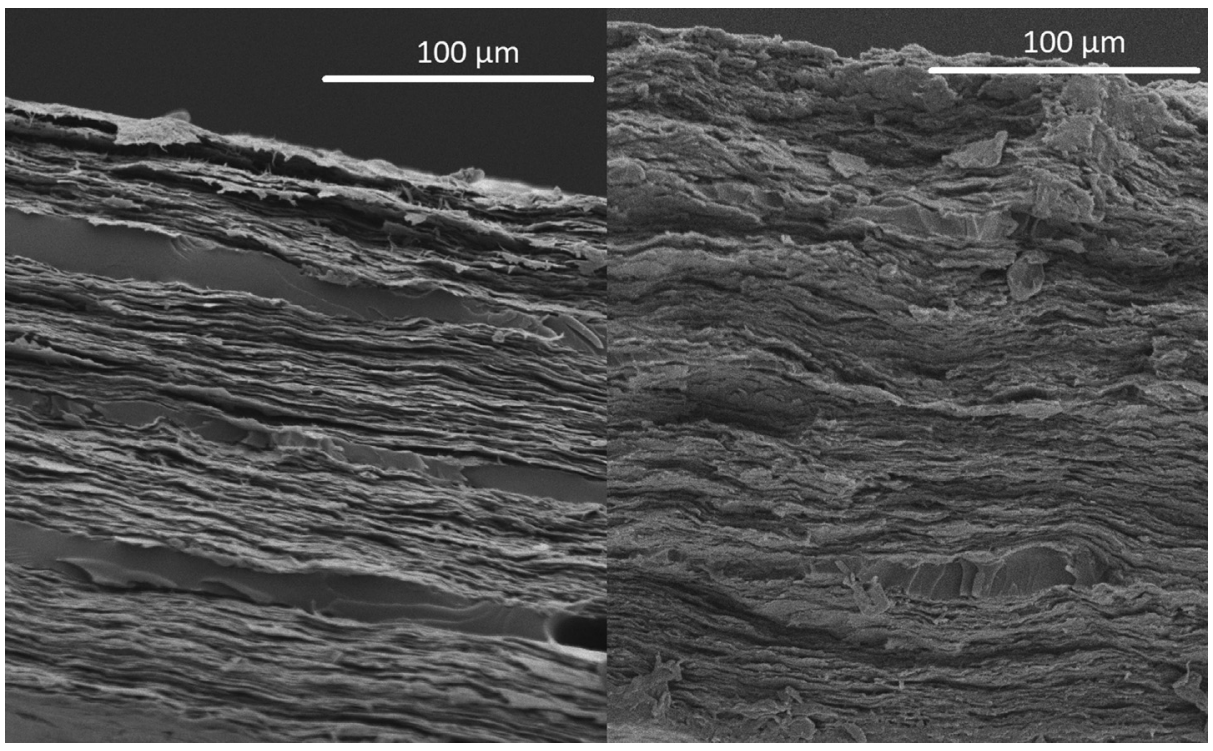

Fig. 4. SEM images of fracture surfaces of 4-layer composites of BC-aq (left) and BC-Et (right) at $300 \times$ magnification.

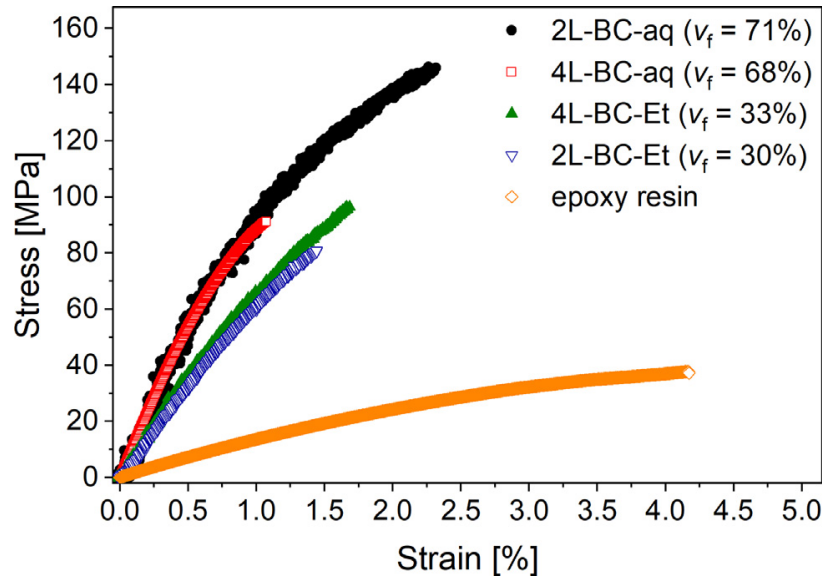

Fig. 5. Representative stress-strain curves of BC-aq and BC-Et composites compared to the neat cured epoxy resin. (For interpretation of the references to colour in this figure legend, the reader is referred to the web version of this article.)

Table 3

Fibre volume fraction $v_{\mathrm{f}}$ and tensile properties of laminated BC-aq and BC-Et papregs as well as the cured epoxy: ultimate tensile strength $(\sigma)$, strain at break $(\varepsilon)$, Young's modulus $(E)$, and storage modulus $\left(E^{\prime}\right)$ at $30{ }^{\circ} \mathrm{C}$ from DMTA.

\begin{tabular}{lllllll}
\hline Sample & $v_{\mathrm{f}}(\%)$ & $\sigma(\mathrm{MPa})$ & $\varepsilon(\%)$ & $E(\mathrm{GPa})$ & $\begin{array}{l}E^{\prime} @ 30{ }^{\circ} \mathrm{C} \\
(\mathrm{GPa})\end{array}$ \\
\hline 2L-BC-aq & $71 \pm 5$ & $150 \pm 11$ & $3.1 \pm 0.5$ & $10.9 \pm 0.2$ & 10.0 \\
4L-BC-aq & $68 \pm 3$ & $95 \pm 4$ & $1.1 \pm 0.1$ & $12.2 \pm 0.7$ & 11.4 \\
2L-BC-Et & $30 \pm 1$ & $83 \pm 12$ & $1.6 \pm 0.4$ & $7.4 \pm 0.6$ & 7.1 \\
4L-BC-Et & $33 \pm 1$ & $100 \pm 10$ & $1.6 \pm 0.1$ & $9.1 \pm 0.7$ & 7.9 \\
Cured epoxy & - & $37.6 \pm 7.1$ & $4.4 \pm 0.9$ & $1.6 \pm 0.1$ & 1.6 \\
\hline
\end{tabular}

laminates compared to BC-aq, a slightly lower Young's modulus (Table 3 ) due to the lower $v_{\mathrm{f}}(33 \%$ vs. $68 \%$ ) had to be accepted. Unexpectedly, 4L-BC-aq laminates had a higher modulus than 2L-BC-aq, even though they exhibited slightly (but not significantly) lower $v_{f}$, while higher $v_{\mathrm{f}}$ usually results in higher modulus in nanopaper composites [40]. This was attributed to the higher grammage of the nanopaper $\left(60 \mathrm{~g} \mathrm{~m}^{-2}\right.$ vs. $50 \mathrm{~g} \mathrm{~m}^{-2}$, see Table 1) used as reinforcement in $4 \mathrm{~L}$ composites, which was done to achieve equivalent $v_{\mathrm{f}}$. In the case of BCEt laminates, higher $v_{\mathrm{f}}$ in $4 \mathrm{~L}-\mathrm{BC}$-Et resulted in a slightly higher modulus

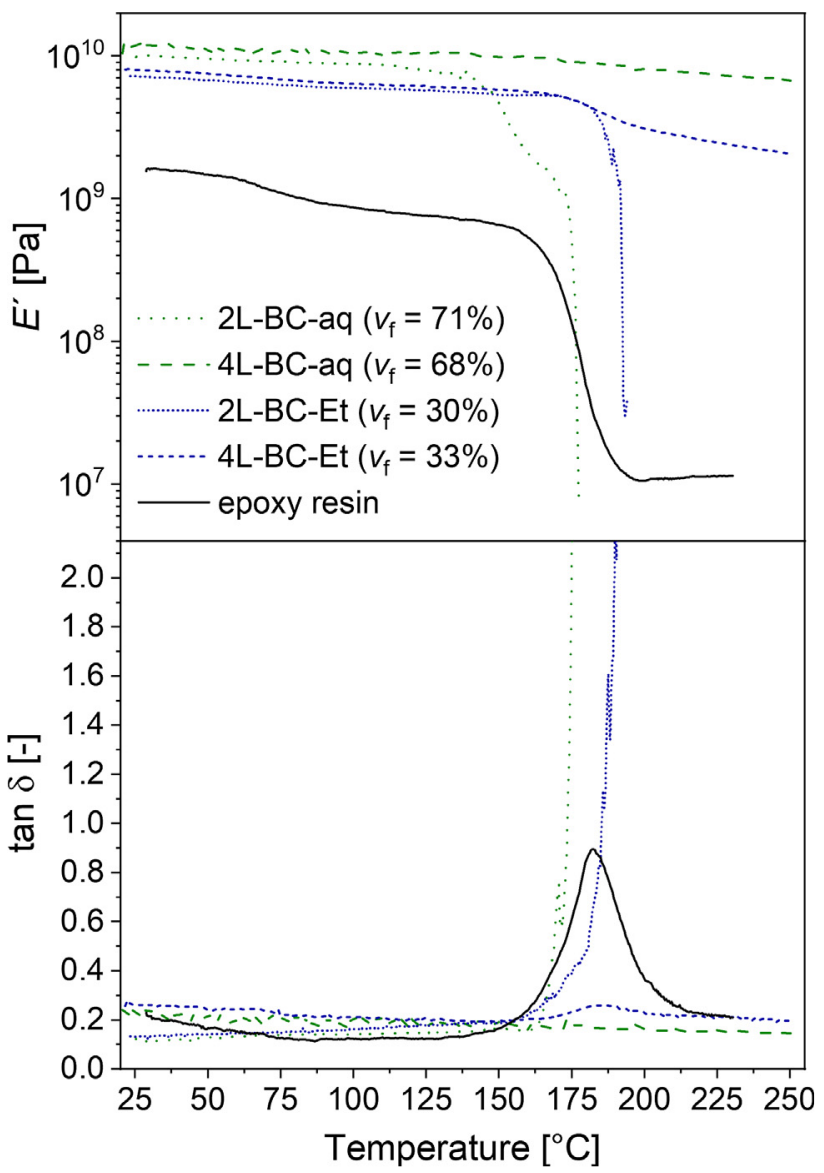

Fig. 6. Storage modulus ( $E^{\prime}$, top) and $\tan \delta$ (bottom) as function of temperature for 2 and 4 layer BC-aq and BC-Et laminates as measured by DMTA. (For interpretation of the references to colour in this figure legend, the reader is referred to the web version of this article.)

compared to 2L-BC-Et.

The temperature-dependence of mechanical properties of composites was analyzed by DMTA as shown in Fig. 6. For BC-aq laminates the storage modulus $\left(E^{\prime}\right)$ linearly decreased with increasing temperature until about $170{ }^{\circ} \mathrm{C}$, which is the onset temperature of $T_{\mathrm{g}}$ of the epoxy 

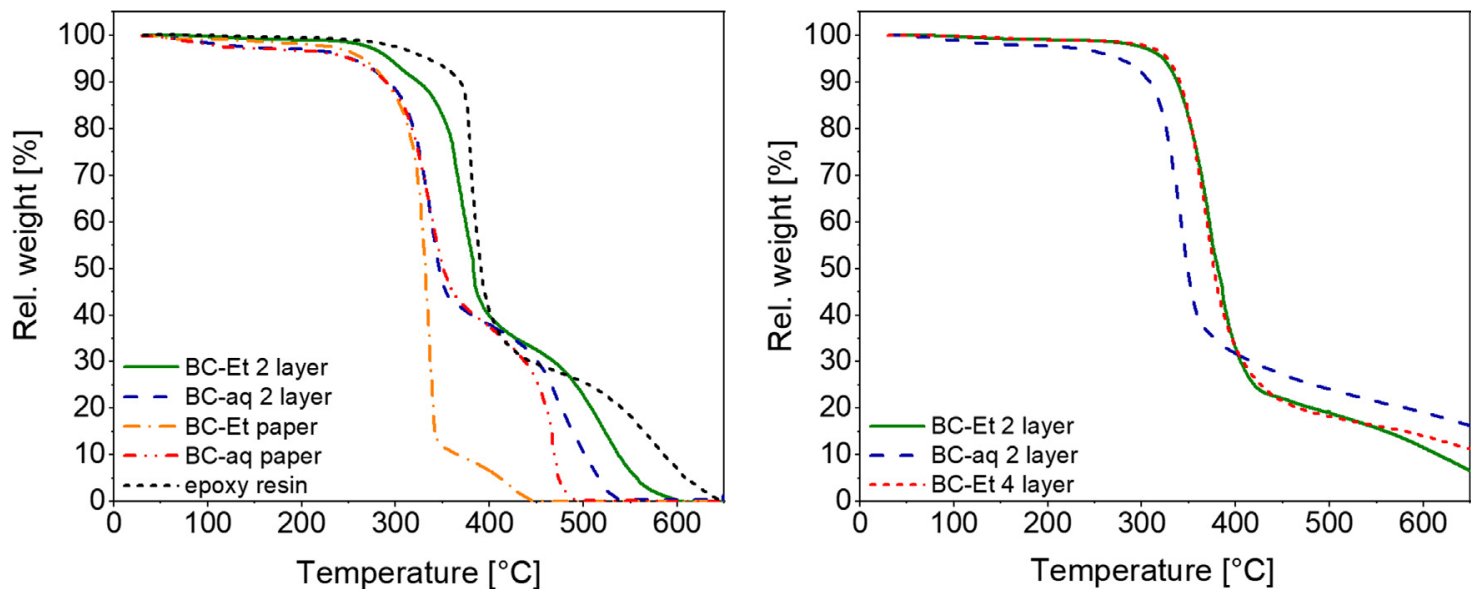

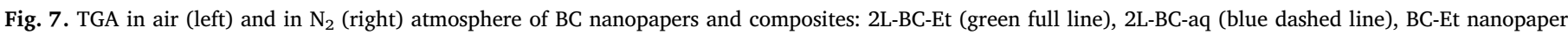

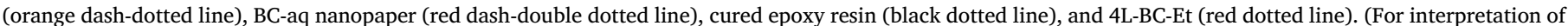
the references to colour in this figure legend, the reader is referred to the web version of this article.)

resin [38], where the storage modulus of the pure cured epoxy resin significantly decreased. Above $170{ }^{\circ} \mathrm{C}$, the storage modulus of $2 \mathrm{~L}-\mathrm{BC}-\mathrm{aq}$ rapidly dropped, while for $4 \mathrm{~L}-\mathrm{BC}$-aq $E^{\prime}$ continued to linearly decrease and remained above $3 \mathrm{GPa}$ up to $250{ }^{\circ} \mathrm{C}$. The latter behaviour is typical for high fibre volume fraction composites and was confirmed by the evolution of $\tan \delta$ with temperature (Fig. 6, bottom). $\tan \delta$ commenced to increase at about $170{ }^{\circ} \mathrm{C}$ for $2 \mathrm{~L}-\mathrm{BC}$-aq whereas for the $4 \mathrm{~L}-\mathrm{BC}$-aq laminates no peak was observed up to $250{ }^{\circ} \mathrm{C}$. Such different behaviour is commonly ascribed to differences in the $v_{\mathrm{f}}$. However, both these composites contained a similarly high $v_{\mathrm{f}}$ of nanocellulose. Therefore, differences were attributed to the thicknesses of the composite structures: Within the much thinner 2L-BC-aq the heat is reaching the bulk of the composite faster. Accordingly, the thin pure resin layer present in the centre of the 2L-BC-aq laminates started to soften at about the glass transition temperature of the resin. Thus, the load bearing capacity declined. However, no rubbery plateau could be observed as the thin, softened material was deformed by the hot air stream from the temperature control system resulting in no reliable data being collected above $170{ }^{\circ} \mathrm{C}$. Conversely, in the $4 \mathrm{~L}$ laminates, heat was slower conducted to the centre of the laminate and hence the pure resin layer did not soften already at this temperature. For BC-Et papregs a similar trend was observed, but at a lower $E^{\prime}$ level. The storage modulus of 2L-BC-Et dropped rapidly at about $180^{\circ} \mathrm{C}$ accompanied by a steep increase in tan $\delta$, whereas the 4L-BC-Et laminate had a storage modulus of more than 1 $\mathrm{GPa}$ at $250{ }^{\circ} \mathrm{C}$. Still, a small peak of $\tan \delta$ was present at the same position as for the neat epoxy resin. Thus, softening occurred also for 4L-BC-Et but due to the higher sample thickness the construct was still able to bear load at this temperature and exhibited a rubbery plateau without being influenced by the heat control system.

Tensile strength and modulus for laminated composites were comparable to those of other nanopaper composites reported in literature. The biggest difference compared to most of those studies was that $v_{\mathrm{f}}$ of the laminates was considerably lower [38]. Aitomäki et al. [31,50] prepared nanopapers from aqueous suspension with or without a solvent exchange step, respectively, followed by vacuum filtration and subsequently used them to prepare composites with a similar $v_{\mathrm{f}}$. Similar or lower tensile strengths of 100 and $72 \mathrm{MPa}$, respectively, were reported for their composites manufactured by a vacuum-infusion process. This process was restricted to a single-layer nanocellulose network, which limited the achievable thickness of the composite. A tensile strength of $80 \mathrm{MPa}$ at $v_{\mathrm{f}}$ of $30 \%$ and a modulus of $8.8 \mathrm{GPa}$ were also found for a freeze-dried single-layer BC mat infused with epoxy resin [37]. Transparent nanopaper-polymer matrix composites [26] for various applications had lower tensile strength of about $70 \mathrm{MPa}$ $[14,62,63]$. Comparable tensile strength for single-layer composites was achieved but only at significantly higher $v_{\mathrm{f}}$ of $55 \%$, while for composites with a similar $v_{\mathrm{f}}$ of $26 \%$ the tensile strength was a mere $50 \mathrm{MPa}$ $[28,29]$. A papreg made from PLA and BC yielded $125 \mathrm{MPa}$ at a $v_{\mathrm{f}}$ of $65 \%$ [36]. Importantly all these approaches were based on impregnating a single nanocellulose network layer, whereby the prepreg and accordingly the composite thickness are inherently limited. The approach reported in this study is intrinsically scalable because there is per se no limit in the numbers of pre-impregnated nanopaper layers that can be laminated thus allowing for the production of thick(er) composite specimens. Reported multi-layer laminated nanopaper thermoplastic composites had comparable mechanical properties of about $100 \mathrm{MPa}$ at significantly higher nanocellulose $v_{\mathrm{f}}[40,41]$. For these composites it was reported that thin single-layer composites had higher tensile strength compared to multi-layer composites, which further decreased with the number of nanopaper/matrix layers added [40]. On the contrary, the present study showed that when using a lamination process with highly porous nanopapers, more layers even improved the tensile strength.

\subsection{Thermal properties of nanopapers and papregs}

The thermal properties of nanopapers and laminates were assessed by thermo-gravimetric analysis in air and in $\mathrm{N}_{2}$ atmosphere, respectively, and differential scanning calorimetry. The glass transition temperature of the pure epoxy resin was determined by DSC to be $167{ }^{\circ} \mathrm{C}$, which was similar to both literature [38] and the onset temperature of $\tan \delta$ in DMTA-results. The $T_{\mathrm{g}}$ of the papregs was 163 and $164^{\circ} \mathrm{C}$, respectively, for 2 and 4 layer BC-aq composites and 176 and $175{ }^{\circ} \mathrm{C}$, respectively, for $2 \mathrm{~L}$ and $4 \mathrm{~L} \mathrm{BC}$-Et composites. Complete curing of the resin was confirmed, in particular for BC-Et laminates. The differences in the $T_{\mathrm{g}}$ between DMTA and DSC were due to the amount of epoxy resin present and thus the extent of the phase transition in the DSC plot. Because of much lower $v_{\mathrm{f}}$, a higher fraction of resin was present for BCEt samples compared to the higher $v_{\mathrm{f}} \mathrm{BC}$-aq laminates and thus, while the onset of the $T_{\mathrm{g}}$ was at similar position, the temperature of the midpoint half height used to determine $T_{\mathrm{g}}$ was shifted to higher temperatures (Fig. S3, supporting information).

The influence of the higher porosity and reduced fibril-fibril interaction in BC-Et networks on the thermal degradation behaviour of both nanopapers and composites is shown in Fig. 7. In both air and in $\mathrm{N}_{2}$ atmosphere, BC-aq laminates lost about $2 \%$ water around $100{ }^{\circ} \mathrm{C}$ whereas BC-Et laminates did not exhibit a detectable water loss. This indicated better resin infusion of the NC network and thus a reduced accessibility of $\mathrm{OH}$ groups of cellulose nanopapers hence possibility of water uptake by the laminates. The onset temperature of the first 
degradation stage in air $\left(280^{\circ} \mathrm{C}\right)$ was essentially the same for BC-aq and BC-Et nanopapers, but a higher fraction of the BC-Et nanopaper already degraded at this stage ( $80 \%$ vs. $50 \%$ ). This indicated the presence of fewer H-bonds in a looser network. The degradation behaviour of the BC-aq nanopaper and the 2L-BC-aq laminate was almost the same. On the other hand, due to the lower $v_{\mathrm{f}}$ in BC-Et laminates and thus the higher epoxy resin content, the onset of thermal degradation shifted by approx. $35^{\circ} \mathrm{C}$ to higher temperatures. In $\mathrm{N}_{2}$ atmosphere (Fig. 7, right) a similar behaviour was found: The BC-Et laminates exhibited improved thermal stability with an onset degradation temperature about $20{ }^{\circ} \mathrm{C}$ higher than for the BC-aq laminates. No detectable difference between 2 and 4 layer composites of BC-Et was observed, which was as expected considering the similar $v_{\mathrm{f}}$ of about $30 \%$. The results obtained from TGA are in line with previously reported results [38]. At high $v_{\mathrm{f}}$, i.e. for BCaq laminates, the degradation behaviour resembled that of the nanopapers they are composed of. On the other hand, lower $v_{\mathrm{f}}$ in BC-Et laminates and thus higher epoxy resin content yielded higher onset temperatures of degradation, demonstrating the protective effect of the matrix which has a higher temperature stability compared to the nanopapers alone. The finding that the onset temperature of degradation decreased with higher $v_{\mathrm{f}}$ confirmed results of a previous study [37].

\section{Conclusions}

Bacterial cellulose (BC) nanopapers were prepared by a papermaking process utilizing filtration from aqueous or ethanol $\mathrm{BC}$ suspensions, respectively. Dispersion of BC-in-ethanol (BC-Et) prior to papermaking resulted in nanopapers with reduced density and hence much higher porosity compared to nanopapers prepared from aqueous suspension (BC-aq). This was attributed to disruption of the hydrogen bond network between nanocellulose fibrils, resulting in BC-Et nanopapers having lower tensile strength and modulus compared to BC-aq nanopapers. Both types of nanopapers were used to prepare multi-layer (2 and 4 layers) laminated nanopaper epoxy composites. The higher porosity of BC-Et nanopapers allowed for improved resin-infusion into the nanopaper networks after lamination, as confirmed by SEM and a reduced void volume fraction, resulting in more translucent composites as compared to laminated BC-aq composites. Papregs with a fibre volume fraction of $71 \%$ containing two BC-aq layers had a tensile strength of $150 \mathrm{MPa}$ whereas two 2L-BC-Et composites with a $v_{\mathrm{f}}$ of only $30 \%$ had a tensile strength of $83 \mathrm{MPa}$. Increasing the number of $\mathrm{BC}$-aq nanopaper layers to four resulted in composites with much lower tensile strength of merely $95 \mathrm{MPa}$. On the other hand 4L-BC-Et laminates had a tensile strength of $100 \mathrm{MPa}$ but contained only half the fibre volume fraction of 4L-BC-aq. This was explained by almost full resin impregnation of the nanocellulose network during consolidation and thus a reduced fraction of voids within the composites ( 3 vol-\%). The thermal stability of BC-Et laminates compared to BC-aq was higher due to a lower fibre volume fraction. Thus, it was shown that improved resin impregnation of highly porous nanocellulose networks results in more translucent composites with better tensile properties even at low fibre volume fractions. Moreover, the composite production process is intrinsically scalable.

\section{CRediT authorship contribution statement}

Andreas Mautner: Conceptualization, Methodology, Investigation, Visualization, Validation, Writing - original draft. Wan M.F.W. Nawawi: Methodology, Investigation, Writing - review \& editing, Funding acquisition. Koon-Yang Lee: Conceptualization, Methodology, Validation, Writing - review \& editing. Alexander Bismarck: Conceptualization, Methodology, Validation, Writing - review \& editing, Supervision, Project administration, Funding acquisition.

\section{Declaration of Competing Interest}

The authors declare that they have no known competing financial interests or personal relationships that could have appeared to influence the work reported in this paper.

\section{Acknowledgements}

The authors acknowledge fzmb for providing BC. WMFWN was supported by the International Islamic University Malaysia and Ministry of Higher Education (Malaysia) and funding by the University of Vienna is also acknowledged.

\section{Appendix A. Supplementary material}

Supplementary data to this article can be found online at https:// doi.org/10.1016/j.compositesa.2020.105779.

\section{References}

[1] Crowther TW, Glick HB, Covey KR, Bettigole C, Maynard DS, Thomas SM, et al. Mapping tree density at a global scale. Nature 2015;525:201.

[2] Røyne F, Peñaloza D, Sandin G, Berlin J, Svanström M. Climate impact assessment in life cycle assessments of forest products: implications of method choice for results and decision-making. J Clean Prod 2016;116:90-9.

[3] Lee K-Y, Aitomäki Y, Berglund LA, Oksman K, Bismarck A. On the use of nanocellulose as reinforcement in polymer matrix composites. Compos Sci Technol 2014;105:15-27.

[4] Pickering KL, Efendy MGA, Le TM. A review of recent developments in natural fibre composites and their mechanical performance. Compos A Appl Sci Manuf 2016;83:98-112.

[5] Jauhari N, Mishra R, Thakur H. Natural fibre reinforced composite laminates - a review. Mater Today Proc 2015;2(4):2868-77.

[6] Gurunathan T, Mohanty S, Nayak SK. A review of the recent developments in biocomposites based on natural fibres and their application perspectives. Compos A Appl Sci Manuf 2015;77:1-25.

[7] Fortea-Verdejo M, Bumbaris E, Burgstaller C, Bismarck A, Lee K-Y. Plant fibre-reinforced polymers: where do we stand in terms of tensile properties? Int Mater Rey 2017;62(8):441-64.

[8] Eichhorn SJ, Dufresne A, Aranguren M, Marcovich NE, Capadona JR, Rowan SJ, et al. Review: current international research into cellulose nanofibres and nanocomposites. J Mater Sci 2010;45:1-33.

[9] Hsieh YC, Yano H, Nogi M, Eichhorn SJ. An estimation of the Young's modulus of bacterial cellulose filaments. Cellulose 2008;15(4):507-13.

[10] Yano H, Sugiyama J, Nakagaito AN, Nogi M, Matsuura T, Hikita M, et al. Optically transparent composites reinforced with networks of bacterial nanofibers. Adv Mater 2005; 17(2):153-5.

[11] Page DH, El-Hosseiny F. Mechanical properties of single wood pulp fibres. Part VI. Fibril angle and the shape of the stress-strain curve. J Pulp Paper Sci 1983;9(4):99-100.

[12] Saito T, Kuramae R, Wohlert J, Berglund LA, Isogai A. An ultrastrong nanofibrillar biomaterial: the strength of single cellulose nanofibrils revealed via sonication-induced fragmentation. Biomacromolecules 2013;14(1):248-53.

[13] Lee K-Y, Tang M, Williams CK, Bismarck A. Carbohydrate derived copoly(lactide) as the compatibilizer for bacterial cellulose reinforced polylactide nanocomposites. Compos Sci Technol 2012;72(14):1646-50.

[14] Iwamoto S, Nakagaito AN, Yano H, Nogi M. Optically transparent composites reinforced with plant fiber-based nanofibers. Appl Phys A-Mater 2005;81(6):CP8CP1112.

[15] Brown AJ. XIX.- The chemical action of pure cultivations of bacterium aceti. J Chem Soc 1886;49:172-87.

[16] Czaja W, Romanovicz D, Brown RM. Structural investigations of microbial cellulose produced in stationary and agitated culture. Cellulose 2004;11(3):403-11.

[17] Iguchi M, Yamanaka S, Budhiono A. Bacterial cellulose - a masterpiece of nature's art. J Mater Sci 2000;35(2):261-70.

[18] Oksman K, Mathew AP, Bondeson D, Kvien I. Manufacturing process of cellulose whiskers/polylactic acid nanocomposites. Compos Sci Technol 2006;66(15):2776-84.

[19] Ray D, Sain S. In situ processing of cellulose nanocomposites. Compos A Appl Sci Manuf 2016;83:19-37.

[20] Lee K-Y, Blaker JJ, Bismarck A. Surface functionalisation of bacterial cellulose as the route to produce green polylactide nanocomposites with improved properties. Compos Sci Technol 2009;69(15-16):2724-33.

[21] Habibi Y. Key advances in the chemical modification of nanocelluloses. Chem Soc Rev 2014;43(5):1519-42.

[22] Qian S, Sheng K. PLA toughened by bamboo cellulose nanowhiskers: role of silane compatibilization on the PLA bionanocomposite properties. Compos Sci Technol 2017;148:59-69.

[23] Lu J, Askeland P, Drzal LT. Surface modification of microfibrillated cellulose for epoxy composite applications. Polymer 2008;49(5):1285-96.

[24] Fortea-Verdejo M, Lee K-Y, Zimmermann T, Bismarck A. Upgrading flax nonwovens: nanocellulose as binder to produce rigid and robust flax fibre preforms. Compos A Appl Sci Manuf 2016;83:63-71. 
[25] Stamm AJ, Harris EE. Chemical processing of wood. New York: The Chemical Pub. Co.; 1953.

[26] Nogi M, Yano H. Transparent nanocomposites based on cellulose produced by bacteria offer potential innovation in the electronics device industry. Adv Mater 2008;20(10):1849-52.

[27] Nakagaito AN, Iwamoto S, Yano H. Bacterial cellulose: the ultimate nano-scalar cellulose morphology for the production of high-strength composites. Appl Phys AMater 2005;80(1):93-7.

[28] Wang B, Li D. Strong and optically transparent biocomposites reinforced with cellulose nanofibers isolated from peanut shell. Compos A Appl Sci Manuf 2015;79:1-7.

[29] Henriksson M, Fogelström L, Berglund LA, Johansson M, Hult A. Novel nanocomposite concept based on cross-linking of hyperbranched polymers in reactive cellulose nanopaper templates. Compos Sci Technol 2011;71(1):13-7.

[30] Siqueira G, Oksman K, Tadokoro SK, Mathew AP. Re-dispersible carrot nanofibers with high mechanical properties and reinforcing capacity for use in composite materials. Compos Sci Technol 2016;123:49-56.

[31] Aitomäki Y, Moreno-Rodriguez S, Lundström TS, Oksman K. Vacuum infusion of cellulose nanofibre network composites: Influence of porosity on permeability and impregnation. Mater Design 2016;95:204-11.

[32] Ansari F, Lindh EL, Furo I, Johansson MKG, Berglund LA. Interface tailoring through covalent hydroxyl-epoxy bonds improves hygromechanical stability in nanocellulose materials. Compos Sci Technol 2016;134:175-83.

[33] Ansari F, Galland S, Johansson M, Plummer CJG, Berglund LA. Cellulose nanofiber network for moisture stable, strong and ductile biocomposites and increased epoxy curing rate. Compos A Appl Sci Manuf 2014;63:35-44.

[34] Ansari F, Skrifvars M, Berglund L. Nanostructured biocomposites based on unsaturated polyester resin and a cellulose nanofiber network. Compos Sci Technol 2015;117:298-306.

[35] Ansari F, Sjöstedt A, Larsson PT, Berglund LA, Wågberg L. Hierarchical wood cel lulose fiber/epoxy biocomposites - Materials design of fiber porosity and nanostructure. Compos A Appl Sci Manuf 2015;74:60-8.

[36] Montrikittiphant T, Tang M, Lee K-Y, Williams CK, Bismarck A. Bacterial cellulose nanopaper as reinforcement for polylactide composites: renewable thermoplastic NanoPaPreg. Macromol Rapid Comm 2014;35(19):1640-5.

[37] Yue L, Liu F, Mekala S, Patel A, Gross RA, Manas-Zloczower I. High performance biobased epoxy nanocomposite reinforced with a bacterial cellulose nanofiber network. ACS Sustain Chem Eng 2019;7(6):5986-92.

[38] Mautner A, Lucenius J, Österberg M, Bismarck A. Multi-layer nanopaper based composites. Cellulose 2017;24(4):1759-73.

[39] Lee KY, Tammelin T, Schulfter K, Kiiskinen H, Samela J, Bismarck A. High performance cellulose nanocomposites: comparing the reinforcing ability of bacterial cellulose and nanofibrillated cellulose. ACS Appl Mater Inter 2012;4(8):4078-86.

[40] Hervy M, Blaker JJ, Braz AL, Lee K-Y. Mechanical response of multi-layer bacterial cellulose nanopaper reinforced polylactide laminated composites. Compos A Appl Sci Manuf 2018;107:155-63.

[41] Hervy M, Bock F, Lee K-Y. Thinner and better: (Ultra-)low grammage bacterial cellulose nanopaper-reinforced polylactide composite laminates. Compos Sci Technol 2018;167:126-33.

[42] Mao R, Goutianos S, Tu W, Meng N, Chen S, Peijs T. Modelling the elastic properties of cellulose nanopaper. Mater Design 2017;126:183-9.

[43] Oksman K, Aitomäki Y, Mathew AP, Siqueira G, Zhou Q, Butylina S, et al. Review of the recent developments in cellulose nanocomposite processing. Compos A Appl Sci
Manuf 2016;83:2-18.

[44] Mautner A, Mayer F, Hervy M, Lee K-Y, Bismarck A. Better together: synergy in nanocellulose blends. Philos T R Soc A 2018;376(2112):20170043.

[45] Mautner A, Lee KY, Lahtinen P, Hakalahti M, Tammelin T, Li K, et al. Nanopapers for organic solvent nanofiltration. Chem Commun 2014;50(43):5778-81.

[46] Mautner A, Lee K-Y, Tammelin T, Mathew AP, Nedoma AJ, Li K, et al. Cellulose nanopapers as tight aqueous ultra-filtration membranes. React Funct Polym 2015;86:209-14.

[47] Aitomäki Y, Oksman K. Reinforcing efficiency of nanocellulose in polymers. React Funct Polym 2014;85:151-6.

[48] Soeta H, Fujisawa S, Saito T, Isogai A. Interfacial layer thickness design for exploiting the reinforcement potential of nanocellulose in cellulose triacetate matrix. Compos Sci Technol 2017;147:100-6.

[49] Ferguson A, Khan U, Walsh M, Lee K-Y, Bismarck A, Shaffer MSP, et al. Understanding the dispersion and assembly of bacterial cellulose in organic solvents. Biomacromolecules 2016;17(5):1845-53.

[50] Jonoobi M, Aitomäki Y, Mathew AP, Oksman K. Thermoplastic polymer impregnation of cellulose nanofibre networks: morphology, mechanical and optical properties. Compos A Appl Sci Manuf 2014;58:30-5.

[51] Sehaqui H, Zhou Q, Ikkala O, Berglund LA. Strong and tough cellulose nanopaper with high specific surface area and porosity. Biomacromolecules 2011;12(10):3638-44.

[52] Lee K-Y, Ho KKC, Schlufter K, Bismarck A. Hierarchical composites reinforced with robust short sisal fibre preforms utilising bacterial cellulose as binder. Compos Sci Technol 2012;72(13):1479-86.

[53] Henriksson M, Berglund LA, Isaksson P, Lindström T, Nishino T. Cellulose nanopaper structures of high toughness. Biomacromolecules 2008;9:1579-85.

[54] Hervy M, Santmarti A, Lahtinen P, Tammelin T, Lee K-Y. Sample geometry dependency on the measured tensile properties of cellulose nanopapers. Mater Design 2017;121:421-9.

[55] Mao R, Goutianos S, Tu W, Meng N, Yang G, Berglund LA, et al. Comparison of fracture properties of cellulose nanopaper, printing paper and buckypaper. J Mater Sci 2017;52(16):9508-19.

[56] Mao R, Meng N, Tu W, Peijs T. Toughening mechanisms in cellulose nanopaper: the contribution of amorphous regions. Cellulose 2017;24(11):4627-39.

[57] Urbina L, Corcuera MÁ, Eceiza A, Retegi A. Stiff all-bacterial cellulose nanopaper with enhanced mechanical and barrier properties. Mater Lett 2019;246:67-70.

[58] I'Anson SJ, Sampson WW, Savani S. Density dependent influence of grammage on tensile properties of handsheets. J Pulp Paper Sci 2008;34(3):182-9.

[59] Przybysz P, Dubowik M, Kucner MA, Przybysz K, Przybysz Buzała K. Contribution of hydrogen bonds to paper strength properties. PLoS ONE 2016;11(5):e0155809.

[60] Toivonen MS, Onelli OD, Jacucci G, Lovikka V, Rojas OJ, Ikkala O, et al. Anomalous-diffusion-assisted brightness in white cellulose nanofibril membranes. Adv Mater 2018;30(16):1704050.

[61] Gustafsson S, Lordat P, Hanrieder T, Asper M, Schaefer O, Mihranyan A. Millefeuille paper: a novel type of filter architecture for advanced virus separation applications. Mater Horiz 2016;3(4):320-7.

[62] Santmarti A, Teh JW, Lee K-Y. Transparent poly(methyl methacrylate) composites based on bacterial cellulose nanofiber networks with improved fracture resistance and impact strength. ACS Omega 2019;4(6):9896-903.

[63] Pinto ERP, Barud HS, Silva RR, Palmieri M, Polito WL, Calil VL, et al. Transparent composites prepared from bacterial cellulose and castor oil based polyurethane as substrates for flexible OLEDs. J Mater Chem C 2015;3(44):11581-8. 